\title{
Editorial
}

\section{Do we really need a new journal?}

\author{
Apurb Sharma*, Bishwas Pradhan** \\ * Shahid Gangalal National Heart Centre, Bansbari, Kathmandu, Nepal. \\ ** Manmohan Cardiothoracic Vascular and Transplant Centre, Institute of Medicine, \\ Maharajgunj, Kathmandu, Nepal.
}

A very valid point: is there a need for a new biomedical journal that publishes contributions of anesthesiologists to medical science? The answer is an emphatic "yes." We are aware of the fact that Nepalese anesthesiologists, intensivists and pain practitioners can make significant contributions to medical knowledge which would be worth mentioning.

Nepal is a country with great geographical variation, ranging from around 70 meters above sea level to 8848 meters and with mountains of the Himalayas, hills and planes of Terai. Diverse ethnicity, morphological and physiological differences among them, exploration, identification and distribution of the findings can be achieved only through publication of such materials and a national biomedical journal would serve immensely for this purpose. A publication that presents work of Nepalese researchers would give a message that they can remain in the front of research efforts, the bottom line of scientific progress.

Publication of a biomedical journal in the field of anesthesia and intensive care, pain medicine and allied science in the country will certainly help to find the approaches to current problems. A journal would facilitate discussions regarding important issues, development of the scientific background for planning and active participation of national anesthesia community in health policy making. A Nepalese journal will encourage new researchers to submit their work for their first publication. For a beginner, it is a process that might serve as an important "first step". It can be an immense encouragement for dedicating time to research. A new journal focusing primarily on Nepalese authorship may also provide the authors a better chance to receive the public appreciation and respect they deserve for pursuing independent research work. The educational benefits associated with the development and production of the journal would be enormous for the editors, publications staff and audience.

"The journey of thousand miles begins with a small step". This famous quote, attributed to the ancient Chinese philosopher Lao-tzu, serves as background to the development of this journal. The first step for this journal was taken nearly 5 years ago during the period of $9^{\text {th }}$ Executive Committee of Society of Anesthesiologists of Nepal (SAN) (2009 to 2011 AD), and under the guidance of this executive committee the first newsletter was published. ${ }^{1}$ The series continued till around 8 newsletters were published in four years which finally shaped in "Journal of Society of Anesthesiologists of Nepal" (JSAN); a mission started with a vision; a fiction moulding in facts.

Corresponding Author:

Apurb Sharma

Anesthesiologist, Department of Anesthesiology, Shahid Gangalal National Heart Centre, Kathmandu, Nepal.

Mob: +9779841221467

Email: apurbsharma1976@gmail.com 
In conclusion, the need for a biomedical journal to publish scientific research distinct to our diverse geography, ethnicity and community was felt within SAN a long ago. JSAN will be a dream come true for all the members, nonmember anesthesiologists, allied technicians and staffs, well wishers and supporters of the society.

\section{References}

1. Marhatta MN. Current status of anesthesiology in Nepal. In: Bulletin, 14 ${ }^{\text {th }}$ SANCON. 2013 April 5-6; Kathmandu, Nepal. 